\title{
Empirical Research of Merger and Acquisition Performance on China's Media Industry Listed Company
}

\author{
Zou xiuling, \\ South China University of Technology department of finance, Guangzhou, Guang Dong, China \\ 2931630159@qq.com
}

Key words: the media industry; Merger and acquisition characteristic; Mergers and acquisitions performance

\begin{abstract}
In recent years, under the strong support of national policy, there was a wave of mergers and acquisitions in China's media industry listed companies. Mergers and acquisitions, however, are of good quantity is not equal to be of good quality and m\&a get real improvement whether the performance of the company after the merger, acquisition characteristics of different changes will affect the performance of m\&a. These are the media mergers and acquisitions of listed companies needed to answer questions. Therefore, based on the Shanghai and shenzhen a-share market in China from 2009 to 2013 in mergers and acquisitions of media listed companies as samples, using the factor analysis method, from the overall comprehensive performance, mergers and acquisitions of enterprise nature, its stake after the merger, mode of payment, whether to belong to the sample in 5 aspects of related party transactions mergers and acquisitions, mergers and acquisitions that year and year before three years after the merger of mergers and acquisitions performance evaluation. The study found that overall performance is improved after the merger, and the highest level of performance is the second year after the merger, but no significant change in the first year after the merger performance, mergers and acquisitions current performance decline. M\&a characteristics different companies changes its m\&a performance is also different.
\end{abstract}

\section{中国传媒上市公司并购绩效的实证研究}

\author{
邹秀玲 \\ 华南理工大学金融系, 广州, 广东, 中国 \\ 2931630159@qq.com
}

关键词：传媒业；并购特征；并购绩效

摘 要: 近年来, 我国传媒产业上市公司受到国家政策的大力支持, 出现了一波又一波的并 购浪潮。然而, 并购数量多并不等于并购质量好, 并购后公司的绩效是否得到真正改善, 并 购特征的不同是否会影响并购绩效的变化。这些都是研究传媒上市公司并购所需回答的问题。 因此，本文以我国沪深 A 股市场 2009-2013 年发生并购的传媒上市公司为样本，运用因子分 析法，从总体综合绩效、并购方的企业性质、并购后的持股比例、支付方式、是否属于关联 交易 5 个方面对样本并购前一年、并购当年及并购后三年的并购绩效进行评价。研究发现， 并购后总体绩效得到改善，且并购后第二年绩效改善程度最高，但并购后第一年绩效无明显 变化，并购当年绩效下降；并购特征不同的公司其并购绩效变化也有所不同。

\section{一、引言}

随着互联网等信息技术的发展与电子设备的普及，新媒体凭借限制少、功能强、易操作 
等特点已逐渐抢占传统传媒企业的市场, 面对行业内的竞争加剧, 如何寻找新的突破口, 不 被技术边缘化, 进一步完善产业链, 已成为各大传统传媒企业的紧迫任务, 越来越多的企业 意识到转型才有重生的希望。2006 年, 政府颁布的《国家 “十一五” 时期文化发展规划纲要》 明确了我国文化产业中的中长期基本发展战略, 确立了积极稳妥的推进文化体制改革的实施 战略。2012 年 2 月 15 日发布的《国家 “十二五” 时期文化改革发展规划纲要》指出，扩大 文化企业对外投资和跨国经营，鼓励具有竞争优势和经营管理能力的文化企业对外投资。新 闻出版总署、财政部等多个部委联合发力, 鼓励和支持文化企业进行并购, 明确提出破除地 区封锁和行业壁垒，支持传媒集团跨媒体、跨地区、跨行业、跨所有制发展，培育多个年销 售额超过 200 亿元的大型传媒集团。因此, 从传媒行业面临的现状及国家的政策支持来看, 并购已成为我国传媒行业转型的主要方式。那么, 传媒行业的并购绩效如何, 是否可以像预 期那样为并购企业带来协同效应，提高企业的核心价值，这些问题都非常值得研究。

\section{二、文献回顾}

国内外学者研究并购绩效, 主要集中在并购绩效方法、收购方的绩效以及影响并购绩效 的因素方面。

并购绩效方法研究方面, 国内外主要有事件研究法和会计研究法两种主流方法。事件研 究法是把企业并购看作独立的研究事件, 通过比较并购发生阶段和未发生阶段的股东收益来 评价并购是否给企业的股东带来收益。该方法的关键是确定事件期, 一般来说, 事件期的时 间跨度越大，并购造成的影响相对越大。该方法最早由 Dolley. J 于 1933 年提出, 随后 Bal1 \& Brown（1968）运用该方法研究了企业的会计盈余报告, Langetieg、Kim、Franks 等学者 运用事件研究法对处于不同时期、具有不同规模的并购活动进行研究, 发现被收购方股东的 累计超额收益获得了显著增长。会计研究法又称财务指标研究法, 该方法主要是通过利用并 购前后公司的财务指标变化来测度当前的并购活动是否对公司绩效产生影响。Meeks (1977) 运用该方法, 以资产收益率为评价指标, 对 1964-1972 年发生的 233 起并购活动研究, 发现 有 $2 / 3$ 的样本公司收购后绩效低于行业平均水平, 且资产收益率逐年下降, 在第五年达到最 低。王宋涛 (2012) 选择盈利指标、自由现金流量指标和费用率指标这三类指标对 2002-2004 年发生并购的 156 家公司进行了并购绩效实证研究。李蕾、宋志国（2009）选择资产收益率、 每股收益、主营业务利润率以及总资产周转率等财务指标, 运用因子分析法对我国证券市场 2006-2008 年发生的并购活动进行了实证研究。

收购方的绩效方面, 关于收购方的绩效如何, 国内外学者尚未得到一致的研究结论。 Ruback、Healy（1992）认为，并购公司的资产收益率显著高于行业平均水平，即并购可以提 高主并公司的绩效。而 Moeller、Sshlingemann (2004) 的研究表明, 并购活动对企业的经营 绩效没有显著影响。吴豪、庄新田 (2008) 等学者同时采用事件研究法和会计指标研究法对 发生并购活动的上市公司进行研究, 发现进行主并上市公司并购后绩效得到短期提升。韩立 岩、陈庆勇 (2007) 通过运用财务指标研究法对 2001-2003 年发生并购的上市公司考察, 认 为主并公司并购绩效无显著变化。冯根福、吴林江 (2001) 的研究指出, 主并公司并购后短 期绩效有所提升，但长期绩效普遍下降。刘彦（2011）以我国 2003-2008 年发生跨国并购交 易的上市公司为考察对象，指出主并公司在并购后的两年内绩效不断下滑。

影响并购绩效的因素方面, Eebkbo(1983) 以加拿大的并购交易为研究对象, 发现选择现 金和股票混合支付方式比只采用现金或股票单一支付方式能获取更高的超额收益。 Travlos (1987) 通过考察支付方式、并购方式等因素对并购绩效的影响，从而认为股权并购方 式对企业绩效的影响显著且影响是负面的。叶璋礼（2013）从横向并购、纵向并购、混合并 购角度来考察上市公司的并购绩效, 发现横向并购绩效最好, 纵向并购绩效次之, 混合并购 绩效最差。陈涛、李善民 (2011) 通过对不同支付方式下进行上市公司并购绩效研究, 认为 采用股票支付能为收购方带来财富增长，而选择现金支付的收购公司不能获取超额收益。 


\section{三、并购绩效评价体系的构建}

\section{（一）评价方法的选取和模型的构建}

考虑到我国上市公司每年定期报出的财务报表，是根据《企业会计准则》编制，并经过 正规会计师事务所审计，且 CPA、公司高管明确其责任与义务后对外公布的，可信度较高。 而我国证券市场发展时间不长, 事件研究法市场有效的假设前提是否成立争议较大, 所以本 文选择财务指标法评价公司并购绩效。因子分析法是将多个变量通过降维归结为少数几个主 成分，主成分之间的相关性低，并可以最大限度地反映原有变量的信息。

$$
\boldsymbol{F}_{\boldsymbol{t}}=\sum \boldsymbol{a}_{\boldsymbol{t m}} \boldsymbol{f}_{\boldsymbol{i m}} \quad \mathrm{t}=-1,0,1,2,3 ; \quad \mathrm{i}=1,2, \cdots, 26 ; \mathrm{m}=1,2,3 \cdots, 10
$$

其中, $F_{t}$ 代表样本第 $\mathrm{t}$ 年并购绩效的综合得分; $a_{t m}$ 代表样本第 $\mathrm{t}$ 年第 $\mathrm{m}$ 个公共因子的 方差贡献率; $f_{i m}$ 代表第 $\mathrm{i}$ 个公司第 $\mathrm{t}$ 年第 $\mathrm{m}$ 个公共因子的得分。

\section{（二）样本的选取}

本文在 WIND 数据库中选取我国沪深 A 股市场 2009-2013 年进行并购重组的 32 家传媒上 市公司为最初样本, 根据以下标准对最初样本进行筛选, 同时满足标准的样本保留, 其余的 剔除。上市公司的地位是收购方, 并购行为最终成功完成, 财务数据完整, 没有被 ST 或 *ST, 同一年多次发生并购的以金额最大的为样本，最终选取 26 家并购公司为研究样本。

\section{（三）财务指标的选取}

根据 2002 年颁发的《企业绩效评价操作细则 (修订)》的通知, 以其规定的企业绩效评 价的基本指标和修订指标为依据, 本文选取反映企业财务效益、营运能力、发展能力三方面 状况的 10 个财务指标作为上市公司并购价值效应的评价体系（见表 1）。

表 1 我国传媒上市公司并购绩效的财务指标体系

\begin{tabular}{|c|c|c|}
\hline 指标类型 & 指标名称 & 指标说明 \\
\hline \multirow{5}{*}{ 财务效益 } & 每股收益 & 归属普通股股东的当期净利润/当期发行在外普通股的加权平均数 \\
\hline & 净资产收益率 & 净利润/平均净资产 $* 100 \%$ \\
\hline & 资产报酬率 & （净利润+利息费用+所得税）/平均资产总额 $* 100 \%$ \\
\hline & 主营业务利润率 & 主营业务利润/主营业务收入*100\% \\
\hline & 销售毛利率 & （销售收入-销售成本）/销售收入 $* 100 \%$ \\
\hline \multirow{2}{*}{ 营运能力 } & 总资产周转率 & 主营业务收入/平均资产总额 $* 100 \%$ \\
\hline & 流动资产周转率 & 主营业务收入/平均流动资产总额 $* 100 \%$ \\
\hline \multirow{3}{*}{ 发展能力 } & 净资产增长率 & $\begin{array}{c}\text { (期末扣除其他资本公积的净资产/期初扣除其他资本公积的净资 } \\
\text { 产-1）*100\% }\end{array}$ \\
\hline & 总资产增长率 & 本年总资产增长额/年初总资产*100\% \\
\hline & 净利润增长率 & （本期净利润总额-上期净利润总额）/上期净利润总额 $* 100 \%$ \\
\hline
\end{tabular}

\section{四、上市公司并购绩效的实证分析}

本文采用因子分析法通过 2009-2013 年发生并购的 26 家传媒上市公司的 10 个财务指 标，对并购当年、并购发生前一年以及并购后三年，共五年的并购绩效分别进行分析。

\section{（一）有效性和可行性检验}

进行 KMO 检验和巴特利特球形检验, 当 KMO 值大于 0.5 , Bartlett 球体检验高度显著, 说明样本的财务指标数据适用于因子分析。由表 2 可以看出各年的 KMO 均大于 0.5 , Bartlett 球体检验显著性为 0 , 小于 0.05 , 为高度显著。 
表 2 并购当年巴特利球形检验和 KMO 检验结果

\begin{tabular}{c|c|c|c|c|c|c}
\hline \multicolumn{2}{c|}{ 年份 } & $\mathrm{t}-1$ & $\mathrm{t}$ & $\mathrm{t}+1$ & $\mathrm{t}+2$ & $\mathrm{t}+3$ \\
\hline \multicolumn{2}{c|}{$\begin{array}{c}\text { 取样足够度的 } \\
\text { Kaiser-Meyer-0kin 度量 }\end{array}$} & 0.606 & 0.523 & 0.559 & 0.539 & 0.544 \\
\hline \multirow{4}{*}{$\begin{array}{c}\text { Bartlett 的球形度 } \\
\text { 检验 }\end{array}$} & $\begin{array}{c}\text { 近似 } \\
\text { 卡方 }\end{array}$ & 314.789 & 270.917 & 284.397 & 253.425 & 226.660 \\
\cline { 2 - 7 } & $\mathrm{df}$ & 66 & 66 & 66 & 66 & 66 \\
\cline { 2 - 8 } & Sig. & 0 & 0 & 0 & 0 & 0 \\
\hline
\end{tabular}

\section{（二）主成分的提取}

计算相关系数矩阵和载荷矩阵，以特征值大于 1 为原则提取出公共因子，确定每个公共 因子的方差贡献率。由表 3 可以看出并购各年前三个因子的累计旋转载荷分别为 $74.002 \%$ 、 $66.971 \% 、 65.826 \% 、 64.538 \% 、 61.919 \%$ ，因此提取三个主成分分别表示为 $f_{t 1} 、 f_{t 2} 、 f_{t 3}$ 。

表 3 并购各年解释的总方差

\begin{tabular}{|c|c|c|c|c|c|c|c|c|c|c|}
\hline \multirow{2}{*}{$\begin{array}{l}\text { 年 } \\
\text { 份 }\end{array}$} & \multirow{2}{*}{$\begin{array}{l}\text { 成 } \\
\text { 分 }\end{array}$} & \multicolumn{3}{|c|}{ 初始特征值 } & \multicolumn{3}{|c|}{ 提取平方和载入 } & \multicolumn{3}{|c|}{ 旋转平方和载入 } \\
\hline & & 合计 & $\begin{array}{l}\text { 方差 } \\
\text { 的 \% }\end{array}$ & $\begin{array}{c}\text { 累 } \\
\text { 积 \% }\end{array}$ & 合计 & $\begin{array}{l}\text { 方差 } \\
\text { 的 \% }\end{array}$ & $\begin{array}{c}\text { 累 } \\
\text { 积 \% }\end{array}$ & 合计 & $\begin{array}{l}\text { 方差 } \\
\text { 的 \% }\end{array}$ & $\begin{array}{c}\text { 累 } \\
\text { 积 \% }\end{array}$ \\
\hline \multirow{3}{*}{$\mathrm{t}-1$} & 1 & 4.883 & 34.88 & 34.88 & 4.883 & 34.88 & 34.88 & 3.952 & 28.23 & 28.23 \\
\hline & 2 & 3.907 & 27.906 & 62.785 & 3.907 & 27.906 & 62.785 & 3.345 & 23.89 & 52.12 \\
\hline & 3 & 1.57 & 11.217 & 74.002 & 1.57 & 11.217 & 74.002 & 3.064 & 21.882 & 74.002 \\
\hline \multirow{3}{*}{$\mathrm{t}$} & 1 & 4.803 & 34.311 & 34.311 & 4.803 & 34.311 & 34.311 & 3.56 & 25.43 & 25.43 \\
\hline & 2 & 3.145 & 22.466 & 56.777 & 3.145 & 22.466 & 56.777 & 3.529 & 25.204 & 50.634 \\
\hline & 3 & 1.427 & 10.195 & 66.971 & 1.427 & 10.195 & 66.971 & 2.287 & 16.337 & 66.971 \\
\hline \multirow{3}{*}{$\mathrm{t}+1$} & 1 & 4.063 & 29.02 & 29.02 & 4.063 & 29.02 & 29.02 & 3.894 & 27.813 & 27.813 \\
\hline & 2 & 3.084 & 22.028 & 51.047 & 3.084 & 22.028 & 51.047 & 2.776 & 19.83 & 47.643 \\
\hline & 3 & 2.069 & 14.779 & 65.826 & 2.069 & 14.779 & 65.826 & 2.546 & 18.183 & 65.826 \\
\hline \multirow{3}{*}{$t+2$} & 1 & 4.488 & 32.059 & 32.059 & 4.488 & 32.059 & 32.059 & 4.24 & 30.284 & 30.284 \\
\hline & 2 & 2.732 & 19.511 & 51.57 & 2.732 & 19.511 & 51.57 & 2.811 & 20.078 & 50.362 \\
\hline & 3 & 1.815 & 12.968 & 64.538 & 1.815 & 12.968 & 64.538 & 1.985 & 14.176 & 64.538 \\
\hline \multirow{3}{*}{$t+3$} & 1 & 3.806 & 27.186 & 27.186 & 3.806 & 27.186 & 27.186 & 3.656 & 26.112 & 26.112 \\
\hline & 2 & 2.925 & 20.892 & 48.078 & 2.925 & 20.892 & 48.078 & 2.982 & 21.3 & 47.412 \\
\hline & 3 & 1.938 & 13.841 & 61.919 & 1.938 & 13.841 & 61.919 & 2.031 & 14.507 & 61.919 \\
\hline
\end{tabular}

\section{（三）综合得分函数}

利用成分得分系数矩阵计算出每个公共因子的得分，以各个公共因子的方差贡献率作为 该公共因子得分的权重，计算出该年度并购绩效的综合得分。

并购前一年: $F_{-1}=0.37972 * f_{-11}+0.36634 * f_{-12}+0.25394 * f_{-13}$

并购当年: $F_{0}=0.36734 * f_{01}+0.35975 * f_{02}+0.27291 * f_{03}$

并购后一年: $F_{1}=0.37293 * f_{11}+0.34532 * f_{12}+0.28175 * f_{13}$

并购后两年: $F_{2}=0.38985 * f_{21}+0.36869 * f_{22}+0.24146 * f_{23}$

并购后三年: $F_{3}=0.37647 * f_{31}+0.36542 * f_{32}+0.25811 * f_{33}$ 


\section{（四）计算各年的综合得分}

图 1 并购各年总体绩效得分

\section{绩效得分}

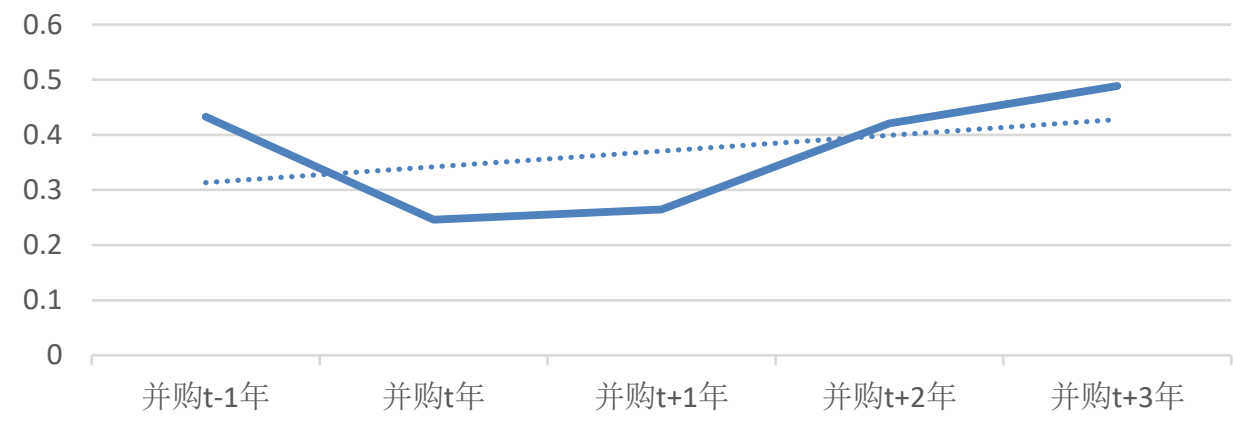

根据因子分析得到以上综合得分的函数, 再将不同年度的三个公共因子得分依次带入上 述公式，求得各个年度公司并购的平均综合得分分别为:

$F_{-1}=0.435213, \quad F_{0}=0.263432, \quad F_{1}=0.265673, \quad F_{2}=0.446745, \quad F_{3}=0.498764$

从图 1 可以看出, 并购当年绩效下降, 并购后第一年绩效无明显变化, 并购后第二年绩 效显著提升, 并购后第三年绩效再次提升, 但变化幅度没有并购后第二年大。整体而言, 并 购后上市公司绩效呈上升趋势，并购可以提高传媒上市公司的绩效，增加股东财富。

\section{五、讨论}

\section{（一）样本的描述性统计}

本文从 WIND 数据库中收集 2009-2013 年发生并购的 26 家传媒上市公司各类信息, 进行 整理统计（见表 4)。

表 4 不同特征下样本的并购绩效得分

\begin{tabular}{|c|c|c|c|c|c|c|c|}
\hline 分类 & 项目 & $\begin{array}{l}\text { 样本 } \\
\text { 数 }\end{array}$ & $\mathrm{t}-1$ & $\mathrm{t}$ & $\mathrm{t}+1$ & $\mathrm{t}+2$ & $t+3$ \\
\hline \multirow{2}{*}{$\begin{array}{l}\text { 企业 } \\
\text { 性质 }\end{array}$} & 国有 & 13 & 0.44107 & 0.273378 & 0.226896 & 0.402078 & 0.483519 \\
\hline & 非国有 & 13 & 0.424851 & 0.218796 & 0.301983 & 0.439229 & 0.493762 \\
\hline \multirow{3}{*}{$\begin{array}{l}\text { 持股 } \\
\text { 比例 }\end{array}$} & 完全 & 9 & 0.417605 & 0.235179 & 0.251146 & 0.443076 & 0.514184 \\
\hline & 多数 & 14 & 0.444754 & 0.248699 & 0.275331 & 0.431687 & 0.486608 \\
\hline & 少数 & 3 & 0.423991 & 0.266622 & 0.25349 & 0.301898 & 0.421493 \\
\hline \multirow{3}{*}{$\begin{array}{l}\text { 支付 } \\
\text { 方式 }\end{array}$} & 发行股份 & 7 & 0.431054 & 0.257658 & 0.253064 & 0.467636 & 0.512448 \\
\hline & 现金 & 7 & 0.440922 & 0.276834 & 0.263366 & 0.362601 & 0.48182 \\
\hline & 发行股份+现金 & 12 & 0.429428 & 0.221402 & 0.271701 & 0.427111 & 0.478731 \\
\hline \multirow{2}{*}{$\begin{array}{l}\text { 关联 } \\
\text { 属性 }\end{array}$} & 关联交易 & 15 & 0.420663 & 0.241581 & 0.262361 & 0.475781 & 0.512827 \\
\hline & 非关联交易 & 11 & 0.449729 & 0.252232 & 0.267274 & 0.345479 & 0.455659 \\
\hline
\end{tabular}




\section{（二）企业性质不同下并购绩效差异}

图 2 企业性质不同下并购绩效变化

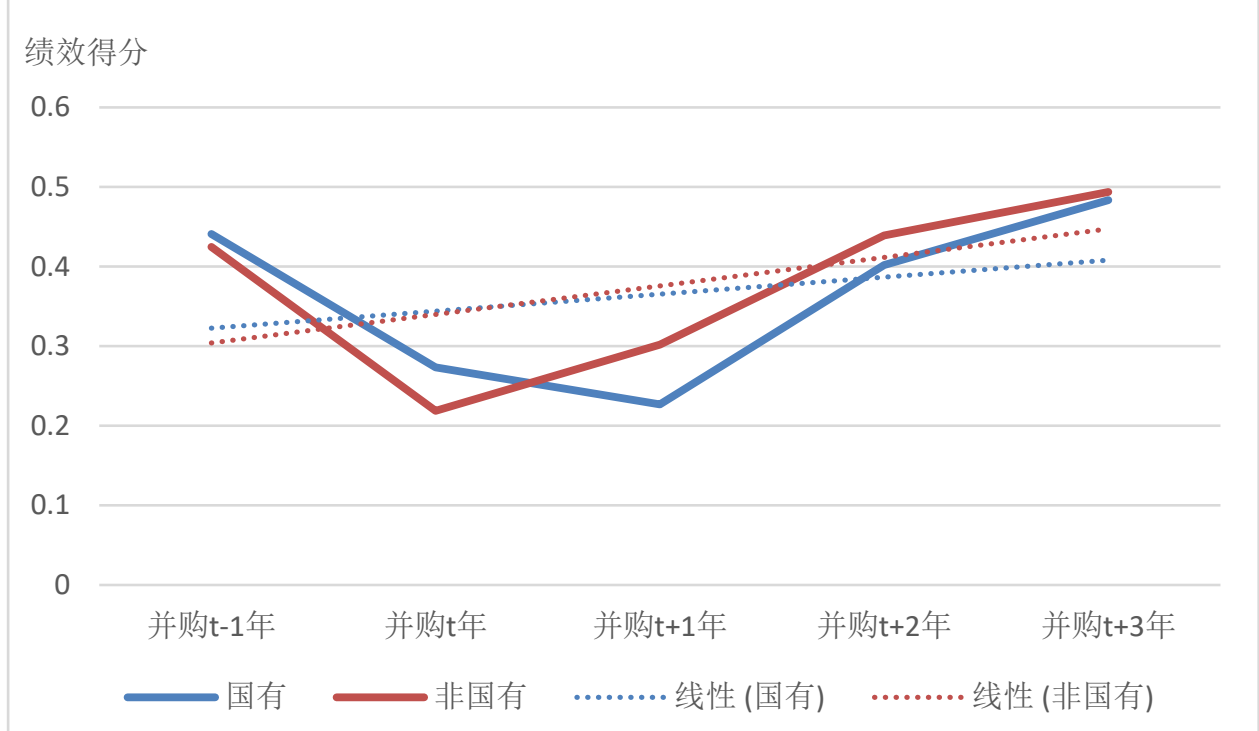

根据企业性质的不同，可分为国有控股与非国有控股，并购绩效变化如图 2。从图 2 中 可以看出, 国有性质的传媒上市公司在并购后第二年绩效开始逐渐提升, 并购当年及并购后 一年内绩效下降；而民营性质的传媒上市公司的绩效在并购当年绩效下降，并购后三年内绩 效稳步提升, 且绩效提升明显好于国有企业。这主要是由于民营企业大多规模为中小型，具 有灵活的管理机制、受政府对并购决策的影响相比国有控股企业小; 较低的运营成本、管理 运营部门设置更合理，大大缩减了管理费用开支。国有控股企业承担着维持社会稳定，提供 就业岗位等社会责任, 政府会鼓励经营绩效好的国有企业兼并濒临破产的企业, 则会导致国 有企业绩效下降。国有控股企业的管理体制落后，管理者通常是公司的实际控制人，所有者 不能有效地监管高管日经营管理活动。但国有控股企业拥有自身的优势, 更容易以较低的价 格获取资源，容易从银行获得贷款，并购当年的绩效高于民营控股公司。

\section{（三）持股比例不同下并购绩效差异}

按并购后持有目标公司的股份比例不同，可分为完全持股（100\%)、多数持股 (51\%-99\%)、 少数持股 (0-50\%), 三种持股比例不同下的绩效变化如图 3。从图 3 可知, 三种持股比例下 的传媒上市公司并购绩效都呈现先下降后上升的趋势, 即并购当年绩效恶化, 并购后第一年 绩效稍有改善, 并购后第二年开始绩效显著提升。其中，完全持股和多数持股比例下的传媒 上市公司并购绩效大体相当, 但两者都明显高于少数持股比例并购绩效。这主要是由于传媒 上市公司拥有对目标公司的控制权后，对目标公司的各种资源具备更强的支配权力，可以最 大限度地进行资源整合，从而获取并购收益。 
图 3 持股比例不同下并购绩效变化

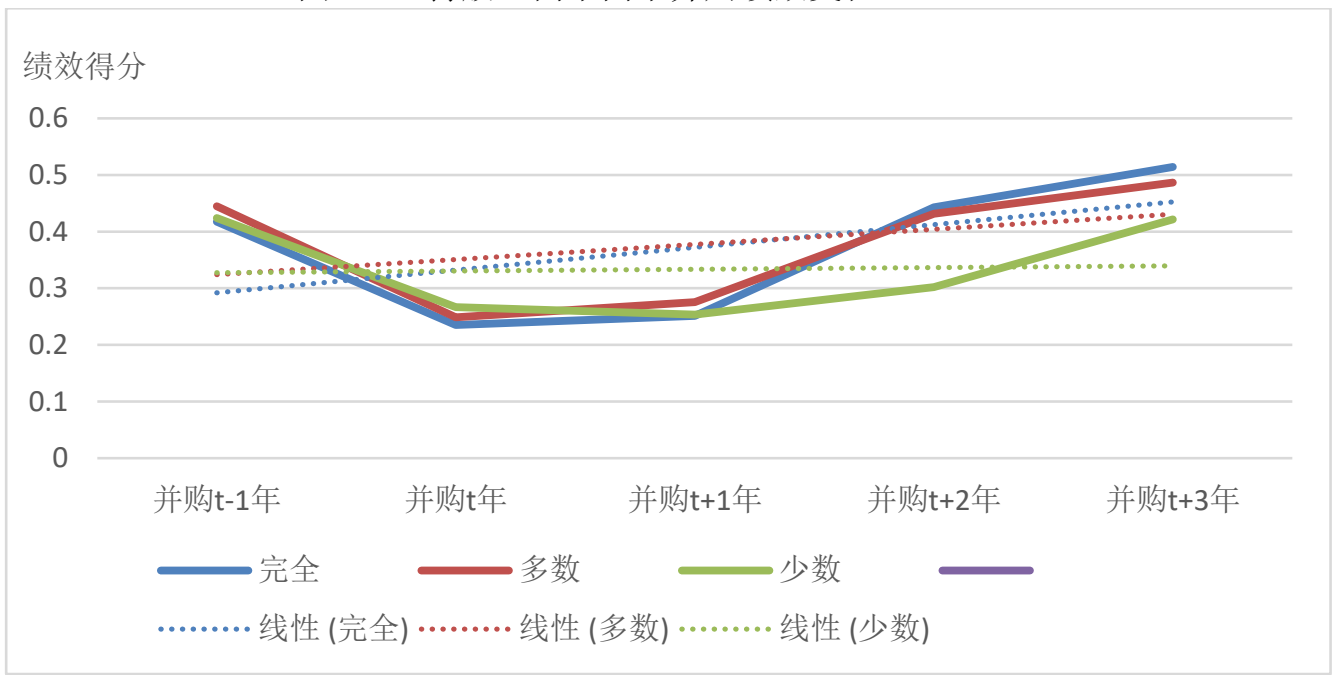

\section{（四）支付方式不同下并购绩效差异}

根据传媒上市公司并购时支付方式的不同，可分为发行股份收购、现金收购、发行股份 加现金收购三种类型，支付方式不同的绩效变化如图 4。从图 4 可知，三种支付方式下的并 购绩效都在并购当年下降, 并购后三年逐渐上升, 其中并购后第二年绩效提升程度最大。三 种方式下，发行股份进行并购的绩效变化更好，仅使用现金进行并购的绩效改善程度最差。 可能的原因在于，一方面，公司现金主要来源于自有资金和银行贷款，而并购所需资金数目 巨大，若以自有资金支付会挤占公司的经营现金流，降低经营效率和偿债能力; 若以银行贷 款支付则会改变公司的资本结构，提高再融资成本，使公司面临巨大的经营压力，巨额现金 流的流出将影响公司的运营周转和后期成长。另一方面, 若以股票方式支付时, 目标企业的 管理层作为传媒上市公司的股东, 要与其共担风险、共享收益, 因此, 他们会主动获取信息 来评估传媒上市公司的发展前景, 同时接受股票形式的支付方式也传递出他们对收购公司未 来获利能力的肯定，从而减少传媒上市公司与目标企业之间的信息不对称。

图 4 支付方式不同下并购绩效变化

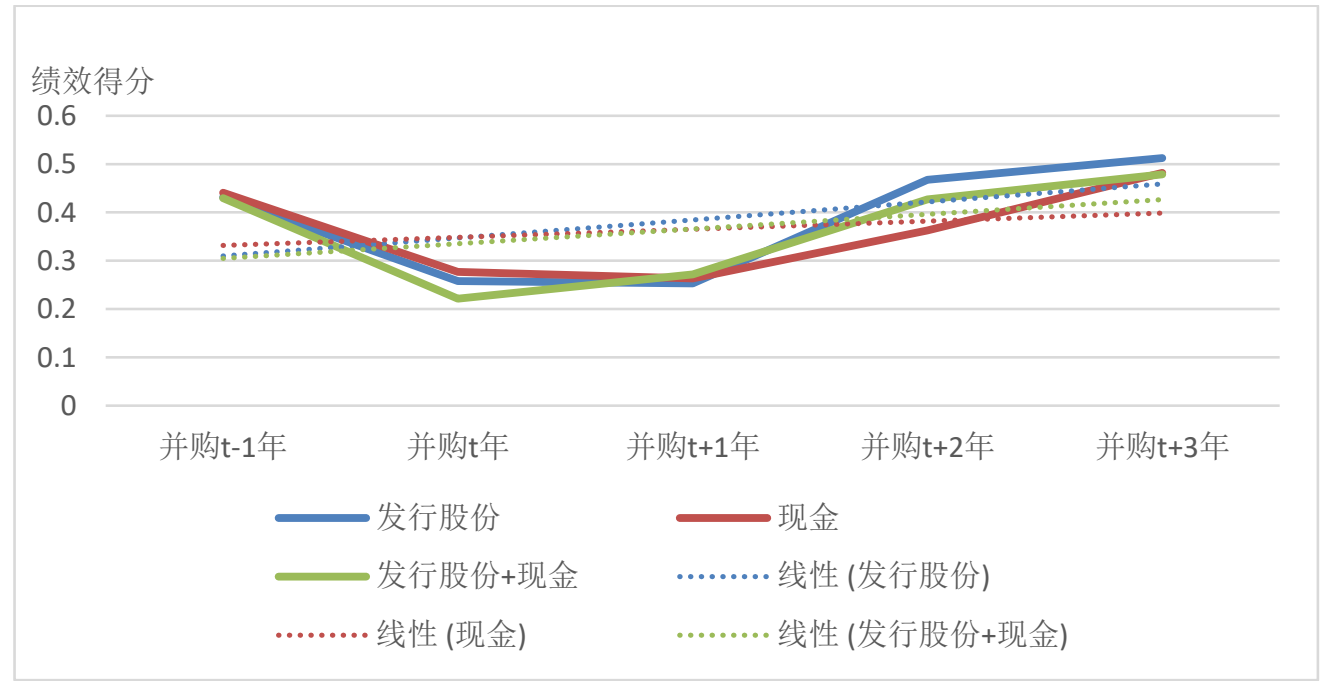




\section{（五）关联属性不同下并购绩效差异}

图 5 关联属性不同下并购绩效变化

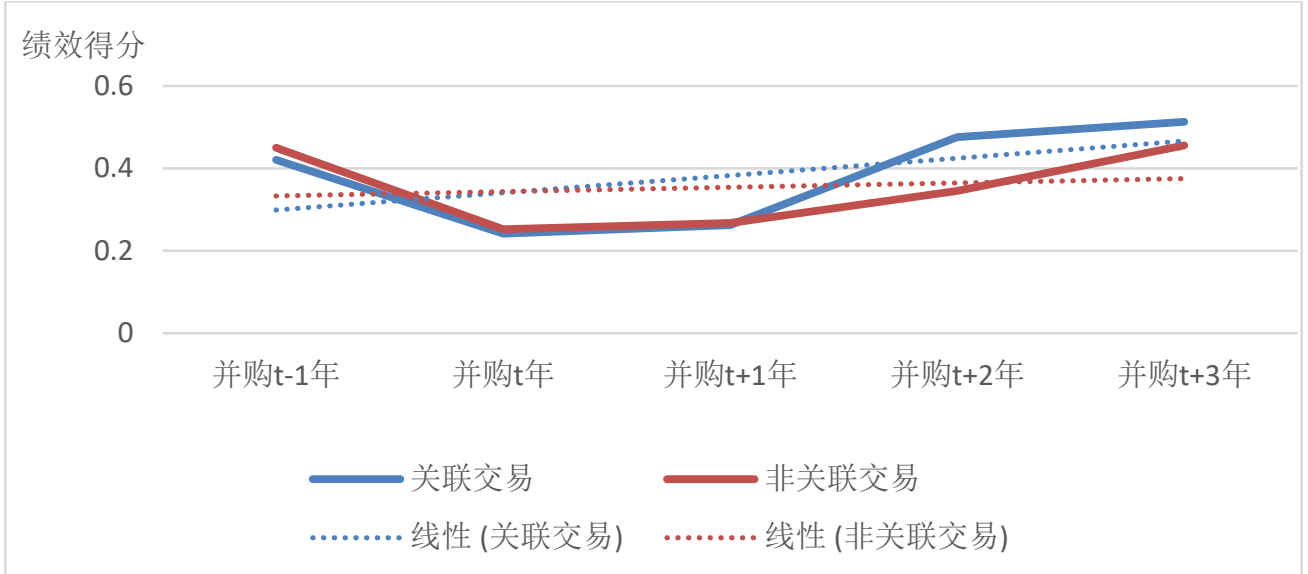

根据并购双方的关联关系不同，属于关联交易的有 15 起 ，占样本量的 $57.7 \%$ ，属于非 关联方交易占 $42.3 \%$, 关联属性不同的绩效变化如图 5。从图 5 中可以看出，关联交易的并购 绩效好于非关联交易, 且并购后第一年绩效基本无变化, 并购后第二年绩效出现显著提升, 并购当年绩效下降。可能的原因在于，关联并购通常体现为企业集团将其所控制的各种资源 以关联方式转入上市公司, 以期实现业务的整体上市, 但短期内, 不能很好地发挥其整体上 市的作用，从而并购绩效在并购后一年并未得到改善; 但是由于传媒的本质在于内容生产, 其竞争优势在于产业链的完整，从长期来看，通过关联交易的并购不仅可以完善产业链，而 且在降低交易成本和信息不对称程度上较非关联并购具有优势。因此, 关联并购绩效变化好 于非关联并购绩效变化。

\section{六、结语}

\section{(一) 研究发现}

本文基于因子分析法对 2009-2013 年发生并购的 26 家传媒上市公司的并购绩效进行评价, 研究发现:（1）我国传媒上市公司在进行并购后, 整体绩效得到改善, 并且在并购后第二年 绩效改善程度最高, 并购后第三年绩效继续提高, 但并购后第一年绩效无明显变化, 并购当 年绩效下降。（2）非国有传媒上市公司的并购绩效变化好于国有传媒上市公司；（3）多数持 股比例下的并购绩效变化与完全持股比例下的绩效变化好于少数股权并购绩效变化;（4）股 份支付方式下的并购绩效比现金支付方式下的绩效变化更好;（5）关联交易并购的绩效改善 效果好于非关联交易。

\section{(二) 研究启示}

（1）理性并购, 避免盲从

实证结果表明, 我国传媒上市公司并购后绩效并不总是持续上升, 在并购当年绩效下降, 并购后第二年绩效才有明显改善。因此, 公司应清楚地认识到, 并购行为存在较大的风险, 公司的并购决策应基于内外环境对发展的需要以及自身具备的资源和能力而做出的理性选择, 绝不是盲目追随潮流的结果。同时, 不同并购特征对公司并购后的影响广度和深度有所差异, 公司应当综合考虑企业性质、收购比例、支付方式等诸多影响并购绩效的因素, 站在公司长 远稳健经营的角度，做出全面而理性的并购决策。

（2）加强并购后公司的整合问题

公司并购后的整合是公司并购中的重要组成部分，也是影响并购绩效的关键环节。从实证 结果可以看到, 我国传媒上市公司的并购绩效在短期内表现较差。一般来说, 主并企业与目 标企业在组织架构、经营风格、管理理念、企业文化、业绩考评等诸多方面存在较大差别, 能否顺利实现双方整合以发挥协同效应是并购活动能否带来价值增值的关键。为了更好实现 并购, 主并企业首先要了解目标企业的历史沿革, 深入研究目标企业文化的优势劣势, 从而 指导后期文化整合的模式和进程。其次, 主并企业应正确定义目标企业所属的文化范畴, 主 
动识别与客体间的文化差异，有的放矢地促进双方文化融合，从而促进并购绩效的提高。

（3）优化资本结构，设计合理的支付方式

我国传媒上市公司并购交易主要以股票和现金支付方式为主, 采用股票支付方式的并购绩 效相对较好，为了平衡资金的流动性和收益性，企业应当将融资方式与支付方式相匹配，既 实现对资本结构的优化又能提高支付的灵活性。如何设计搭配不同的支付方式需根据企业和 交易的具体情况而定, 值得注意的是, 传媒上市公司在考虑运用何种支付方式时必须考虑企 业中长期绩效的影响。

（4）规范政府的行政干预行为

由于政府具有国有资产产权所有者和管理者的双重身份，将直接影响产权交易等实质内 容, 无法保证交易的平等性和公正性。为了防止政府部门过度干预上市公司并购的市场化行 为, 政府应当只负责管理具有普遍指导意义的政策、法规的制定和执行监督; 设置专门机构 经营管理国有资产并行使国有股股东权益，按照股份公司的普遍运行机制，在国家现有相关 政策的指导下，对企业的行为进行管理和监督; 加强国有股、国有法人股战略调整决策、监 督机制的创新, 促进并购市场活跃; 提高国有股和国有法人股变动的透明度, 维护市场公平 公正。

\section{References}

[1] Meeks G.Disappointing Marriage:A Study of the Gains From Merger. Cambridge , Cambridge University Press.1997.109P.

[2] Servaes, HeariThe value of diversification during the congglomerate merge wave Journal of Finance,1996,1201-1225

[3] Lang,L.and R.M.Stulz,1994,Tobin'sq,corporate diversification, and Firm performance, Journal of Political Economy 102,1248-1280

[4] Eebkbo,R.,1983,Corporate Mergers and Shareholder Wealth Effects. Accounting and Business Research,Vol,27,pp109-129

[5] Michael Bradley,Anand Desai and E.Han Kim,Specialized resources and competition in the market for corporate control [J].Journal of Financial Economics, 1988,11:182-206

[6] Healy, Palepu, Ruback, Does Corporate Performance Improve After Mergers? [J].

Journal of Finance Economics,1992,31:135-175

[7] Gennaro Bernile,Evgeny Lyandres,Alexei Zhdanov.A Theory of Strategic Mergers [J].Reviews of Finance ,2011,16:517-575

[8] Rau Raghavendra Vermaelen.Glamour,Value and the Post-acquisition Performance of Acquiring Firms[J].Journal of Financial Economics, 1998,49: 223-253

[9] Megginson, W.L,Morgan,A \& Nail,L.The Determinants of Positive Longterm Performance in Strategic Mergers:Corporate Focus and Cash[J].Journal of Banking \&Finance 2004,28:523-552.

[10] Wang Songtao, TuBin. China's listed company merger and acquisition performance empirical research, based on the comparative analysis of accounting index and value index [J]. Journal of guangdong business school, 2012 01:66-74

[11] Wu Hao, zhuang SAN tin. The Chinese listed company merger and acquisition performance empirical research [J]. Journal of northeastern university, 2008, 11:284-286

[12] Chen tao, governance. Payment with buy-out firms, wealth effect [J], securities market leader, 2011, 11:49-53 
[13]Ye Zhangli. China's listed company merger and acquisition performance empirical study [J]. Journal of statistics and decision, $2013(7)$ : 165-168

[14] Gen-fu feng, Wu Lin river. An empirical study on m\&a performance of listed companies in China $[\mathrm{J}]$. Journal of economic research, 2001 (01): 54-61.

[15] Li lei, Zhiguo Song. based on factor analysis of an empirical study on m\&a performance of listed companies in China [J]. Journal of technology economy and management research, 2009 (6) : 14 to 20 